https://doi.org/10.11646/bde.43.1.12

\title{
Karyotypic diversity and cryptic speciation: Have we vastly underestimated moss species diversity?
}

\author{
NIKISHA PATEL ${ }^{1 *}$, RAFAEL MEDINA ${ }^{2}$, MATTHEW JOHNSON ${ }^{3} \&$ BERNARD GOFFINET $^{1}$ \\ ${ }^{I}$ Department of Ecology and Evolutionary Biology, University of Connecticut, 75 N. Eagleville Rd. Storrs, CT, 06269 \\ ="bernard.goffinet@uconn.edu; (1) https://orcid.org/0000-0002-2754-3895 \\ ${ }^{2}$ Biodiversidad, Ecología y Evolución, Universidad Complutense de Madrid, C/ José Antonio Novais, 12, 28040 Madrid, Spain

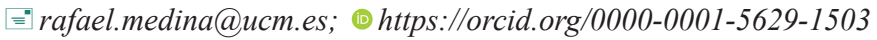 \\ ${ }^{3}$ Department of Biological Sciences, Texas Tech University 2901 Main Street, Lubbock TX 79404 \\ "="matt.johnson@ttu.edu; ○ https://orcid.org/0000-0002-1958-6334 \\ *Corresponding Author: झ"nikisha.patel@uconn.edu; 이ttps://orcid.org/0000-0002-3504-7314
}

\begin{abstract}
Karyotypic diversity is critical to catalyzing change in the evolution of all plants. By resulting in meiotic incompatibility among sets of homologous chromosomes, polyploidy and aneuploidy may facilitate reproductive isolation and the potential for speciation. Across plants, karyotypic variants in the form of allopolyploids receive greater taxonomic attention relative to autopolyploids and aneuploids. In particular, the prevalence and significance of autopolyploidy and aneuploidy in bryophytes is little understood. Using Fritsch's 1991 compendium of bryophyte karyotypes with augmentation from karyological studies published since, we have quantified the prevalence of karyotypic variants among $\sim 1500$ extant morphological species of mosses. We assessed the phylogenetic distribution of karyological data, the frequency of autopolyploidy and aneuploidy, and the methodological correlates with karyotypic diversity. At least two ploidy levels were recorded from $17 \%$ of species potentially increasing current taxonomic diversity of mosses to over 15,000 species. We find that for a given species, the number of unique karyotypes recorded is correlated with the number of populations sampled. The evidence suggests that cytological diversity likely underlies yet undescribed species diversity in mosses, and that intensive karyological sampling is a needed tool for its discovery.
\end{abstract}

Keywords: Bryophyta, polyploidy, autopolyploidy, diversity, taxonomy

\section{Introduction}

In plants, shifts in chromosomal number are linked to sympatric or parapatric speciation through reproductive isolation (Lewis 1980; Schemske 2000; Soltis et al. 2007). Accordingly, consideration for karyotype diversity as another dimension of species delineation is warranted and has the potential to substantially impact taxonomy (Barker et al. 2016). However, detection of these lineages is complicated by the cryptic morphology that is characteristic of plant lineages that are the product of intraspecific genome doubling (Soltis et al. 2007; Eriksson et al. 2017). Within a lineage, variation in chromosome number may be of two types: aneuploid or polyploid. Aneuploids possess an irregular number of chromosomes in a haploid set while polyploids possess full multiple sets of homologs (Tate et al. 2005). Both types of karyotype variants have potential implications for speciation and evolution.

\section{Polyploidy}

Whole genome duplication (WGD), or polyploidy, is common in plants. Conspecific genome doubling (autopolyploidy) or interspecific hybridization followed by genome doubling (allopolyploidy) can produce immediate reproductive isolation from progenitors and related species with lower ploidies, typically referred to as the 'triploid block' (Marks 1966; Köhler et al. 2010). Although ploidal shifts present challenges to reproduction, both pre- and post-zygotically, complicating homolog pairing and segregation in meiosis and syngamy (Jauhar 2003; Svačina et al. 2020), it's clear that these barriers can be overcome given the significance of polyploidy to the diversification of most major plant lineages. In flowering plants, the majority of extant species have undergone polyploidy in their evolutionary history (Cui et al. 2006; Jiao et al. 2011), in ferns an estimated 15-31\% of speciation events involve polyploidy (Wood et al. 
2009), and multiple WGD events have been noted in mosses (Gao et al. 2020). Some mechanisms for overcoming the challenges of reproduction following WGD are known. For instance, the 'triploid bridge,' or reproductively competent triploid individuals resulting from the fusion of an unreduced gamete with the reduced gamete of a diploid parent has been recognized across plant lineages (Husband 2004; Schinkel et al. 2017). Similarly, in ferns, apomictic reproduction is associated with odd-numbered ploidies allowing triploid hybrids to reproduce without syngamy (Grusz 2016; Patel et al. 2018).

\section{Aneuploidy}

Aneuploidy occurs as a result of an aberration in a subset of chromosomes such as chromosomal fusion, fission, or meiotic non-disjunction, or as a consequence of unequal partitioning of chromosomes at meiosis specifically following WGD (Randolph 1935; Doyle 1986; Luceño and Castroviejo 1991; Henry et al. 2010; Zhang et al. 2013). Given that aneuploids can be derived from polyploids, the presence of aneuploidy may signal past WGD (Comai 2005; Mandáková and Lysak 2018). As with polyploids, aneuploids may also experience post-zygotic reproductive isolation from progenitors. The progeny of aneuploid individuals and progenitors often experience reduced fertility reinforcing reproductive isolation of the aneuploid lineage (Xiong et al. 2011; Zhang et al. 2013). Among plants, aneuploidy is a frequently occurring mechanism for speciation in natural populations of model systems Mimulus and Arabidopsis (Vickery 1995; Henry et al. 2010), as well as in crop plants switchgrass and wheat (Costich et al. 2010; Zhang et al. 2013).

\section{Polyploidy, aneuploidy, and diversification}

In plants, WGD is recognized as a critical means of speciation (Otto and Whitton 2000; Wood et al. 2009; Husband et al. 2013). Though autopolyploidy and aneuploidy are known in plants, allopolyploids receive much more research attention and taxonomic recognition (Soltis et al. 2007; 2014; Barker et al. 2016). In part, this is because allopolyploids are more likely to be qualitatively distinct morphologically from their progenitors (Stebbins 1947). However, autopolyploids, though often qualitatively morphologically cryptic, can meet the criteria of various species concepts and thus have been highlighted by many as the next frontier in species discovery in flowering plants and ferns (Soltis et al. 2007; Beck et al. 2010; Barker et al. 2016; Spoelhof et al. 2017).

In mosses, allopolyploidy, once considered infrequent and unimportant to moss speciation and evolution (Vitt 1971; Smith 1978), is now recognized as playing a critical role in ancient and ongoing speciation events (Natcheva and Cronberg 2004; Shaw 2009). Recent studies employ molecular tools including isozymes, microsatellites, and molecular phylogenetics and phylogenomics to elucidate the origins of allopolyploids in the moss families Funariaceae (Beike et al. 2014), Sphagnaceae (e.g., Ricca and Shaw 2010), and Mniaceae (Wyatt et al. 1988) demonstrating the importance of polyploidy in understanding extant species diversity in mosses. However, the significance of other types of karyotype diversity in the context of speciation is underexplored in mosses. In the present study, we review and summarize karyotype diversity in mosses and discuss its implications for speciation and taxonomy among these largely morphologically defined species.

\section{Methods}

\section{Sampling}

We compiled published karyotype data from 12 literature sources ultimately representing 1414 species. Fritsch's (1991) Index to Bryophyte Chromosome Counts provides the vast majority of data as only 11 additional reports seemed to have been published after 1990 (Supplemental File 1).

\section{Data Transcription}

We digitally transcribed all reported moss karyotype data into a Microsoft Excel spreadsheet (Supplemental File 2), recording for each karyotype value: the number of populations studied, the basis for the count (i.e., meiotic vs mitotic divisions), and the number of publications reporting it. For each species we then summarized the karyological spectrum and the total number of studies associated with each chromosome number. We included data indicating $\mathrm{m}$, accessory, fragment, and sex chromosomes.

We excluded counts represented only by an approximation, such as "ca. $n=7$ " or by a range (e. g. " $\mathrm{n}=7-9$ "), and those followed by "?", as well as those counts reported for unidentified species (e.g., "Anomobryum sp."). When main numbers were complemented with a range of accessory chromosomes, we derived a conservative estimate, such that 
" $\mathrm{n}=9+1-5$ " would be recorded as " $\mathrm{n}=10$." When the number of populations was reported as "sev" or "sev?" we reduced this to two populations as the most conservative possible estimate. When a population number was not given, we assumed that at least one was studied. Additional cases requiring adjustments are listed in sheet 2 of Supplemental File 2.

\section{Taxonomic Updates}

The taxonomy and nomenclature of all species in this dataset was updated to reflect the most modern circumscriptions. We recorded and updated the generic name and species epithet (Supplemental File 3) and associated these species with the most up to date family and order names. All taxonomic updates were derived from Tropicos (Tropicos.org or Goffinet 2009). In cases of species names being synonymized following the original karyological publications, the karyological and accessory data were merged into single entries. In instances of taxonomic splitting, the species entry was deleted since it would be impossible to associate the given data with the modern species delineation.

\section{Data Analysis}

Defining ploidy: We assumed that the lowest chromosome count was the base haploid chromosome number, or the lowest haploid chromosome number possible in a natural population. Ploidy and aneuploidy were then defined on the basis of multiples of the base chromosome number.

Assessing autopolyploidy: Any chromosome count that is a whole number multiple of the base chromosome number was counted as a distinct polyploid number. For instance, counts of $n=7,14$, and 21 for a given species, were treated as haploid, diploid, and triploid, respectively. Given that these are apparent duplications within taxa currently defined as species, they are presumed autopolyploids.

Assessing aneuploidy: To quantify aneuploidy, we calculated the number of times multiple relative to base haploid chromosome number. Values that were not whole number multiples of the base haploid chromosome number were considered aneuploids. For instance, a species with counts $n=7$ and $n=10$ was considered to have an aneuploid karyotypic variant.

Proportion autopolyploid and aneuploid species: Only species for which two or more populations were counted (i.e., 893 of the 1414) were retained for subsequent analyses. For each species, autopolyploidy and aneuploidy were scored as present or absent. Autopolyploidy is present based on at least one non-haploid count as defined above independently. Aneuploidy is present based on at least one non-haploid count that is not an even multiple, as defined above, associated with a given species.

The total proportion of species sampled with autopolyploidy and aneuploidy was calculated. The proportion of sampled species that are autopolyploid was calculated for various levels of sampling as represented by number of populations and number of studies. The proportion of autopolyploid species was calculated for the six most sampled families in the dataset.

Autopolyploidy detection correlations: We assessed the relationship between autopolyploidy and sample size in terms of the number of populations sampled and number of studies published. For both, the proportion of species displaying autopolyploidy at sample sizes up to 13 populations, and 12 studies were plotted; a limit chosen as higher values were represented by fewer than ten species each. For both plots, a linear trend line was fitted and the $\mathrm{R}^{2}$ value was calculated to assess the strength of the relationship between either metric of sampling effort and the probability of sampling autopolyploidy. In addition, we assessed the relationship between autopolyploidy and the basis for the counts (i.e., meiotic, mitotic or both types of divisions). The proportion of species associated with each cell type that were also polyploid was calculated.

\section{Results}

\section{Proportion of karyotypic variants}

The final dataset comprised 1414 species, of which 893 were sampled from two or more populations (Supplemental File 3). Among species sampled from two or more populations, $17 \%$ include at least one instance of autopolyploidy and $53 \%$ include at least one instance of aneuploidy or autopolyploidy. Three percent of species included a polyploid series of two or more ploidies (Table 1; Figure 1). Among the six most sampled orders, the mean proportion of species including a polyploid is 0.19 ( $\mathrm{s}=0.08)$ (Supplemental Table 1$)$. 


\section{A}

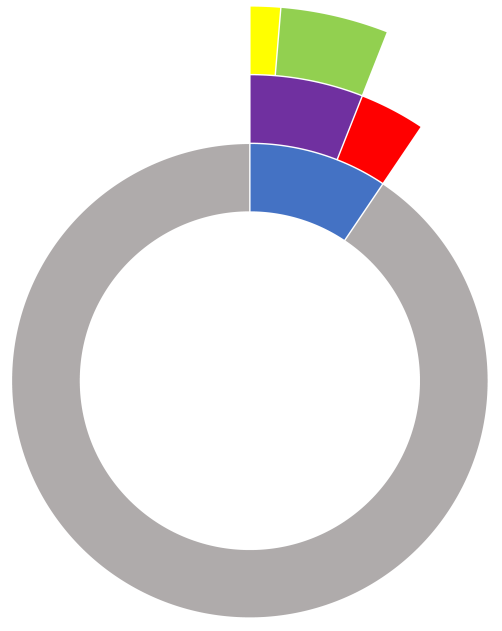

Total species

Karyotyped species

$2+$ populations

1 population

Polyploidy present

Polyploidy absent

B

\section{Whole Number Multiple Karyotypes All Karyotypes}

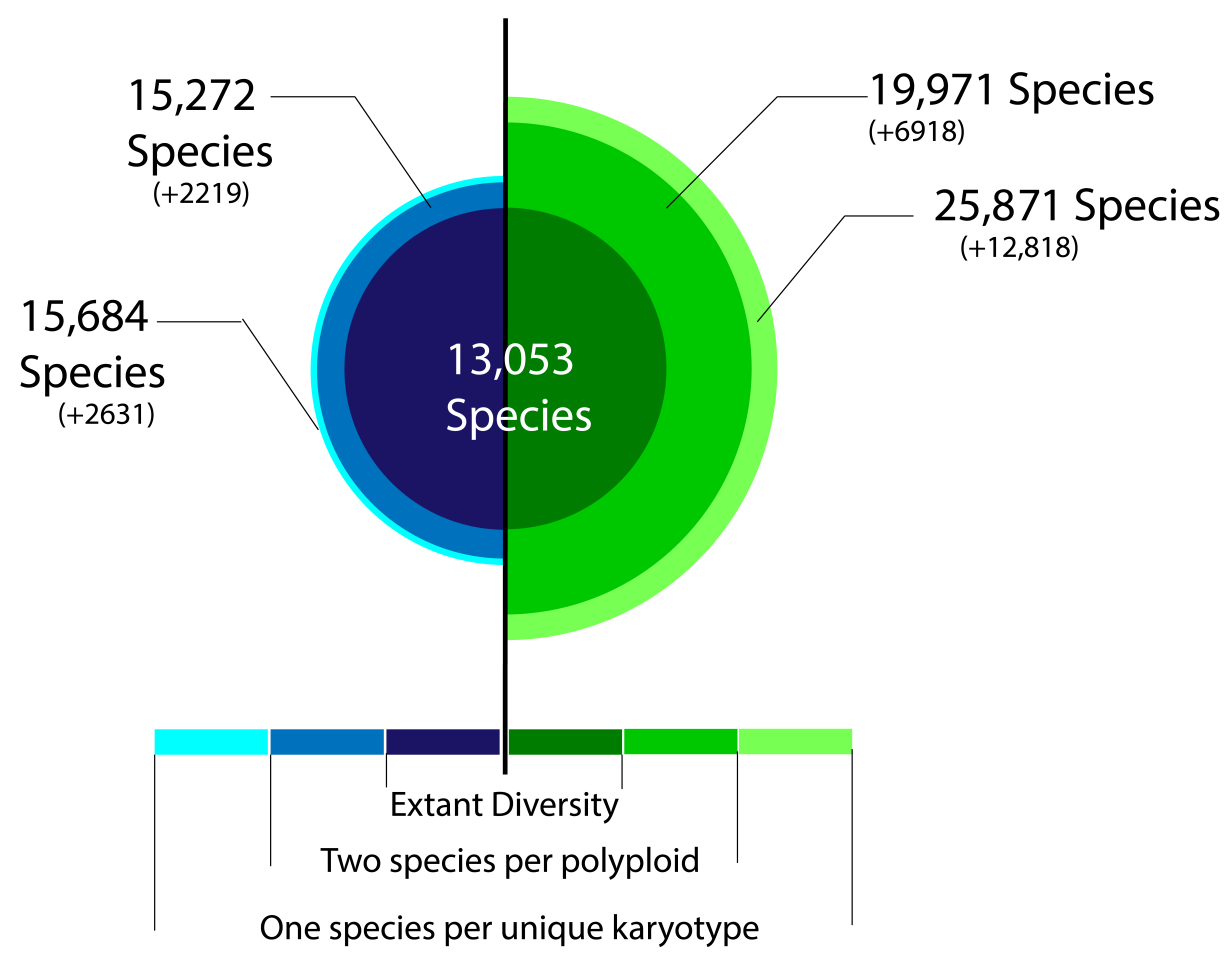

FIGURE 1. A) The innermost ring represents total moss species diversity as estimated by Magill (2010), 13053. Among the karyotyped species, the proportion of species sampled for two or more populations is indicated. Among the species sampled for two or more populations, the proportion including autopolyploid karyotypes is indicated with a wedge at the outer edge. B) Current species diversity and potential species diversity in light of autopolyploids and aneuploids as potential species. The central circle represents accepted species diversity on the basis of Magill (2010). The circle expands proportionately to include potential additional species diversity associated with autopolyploidy (left), as defined in the present study, and any karyotypic variant (autopolyploid or aneuploid) (right). The first concentric circle on each side indicates the increase in species diversity if, as a conservative approach, each species identified as including an autopolyploid or any karyotypic variant, actually constituted two species. The outermost concentric circle on each side indicates the increase in species diversity if each unique karyotype, autopolyploid (left) or any karyotype variant (right), constituted a species. 
TABLE 1. The proportions of species including at least one autopolyploid and aneuploid are given. The proportion of species with three or more autopolyploid counts, with odd numbered autopolyploid counts, and the proportion of species including an autopolyploid count that is also mitotically or meiotically derived are all given. All proportions are calculated out of the number of species for which two or more populations are sampled (893).

\begin{tabular}{lcc}
\hline & Proportion of species & Number of species \\
\hline Autopolyploids (whole number multiple karyotypes) & .17 & 151 \\
Aneuploid and polyploids (all value multiple karyotypes) & .53 & 478 \\
Odd number autopolyploid karyotypes (i.e. 3x, 5x) & .02 & 19 \\
An autopolyploid series (2+ whole number & .03 & 24 \\
multiple karyotypes) & & 10 \\
Species karyotypes derived from mitotic cells & .01 & \\
and having autopolyploid karyotypes & .06 \\
Species karyotypes derived from meiotic cells \\
and having autopolyploid karyotypes
\end{tabular}

\section{Sampling correlations}

Species karyotypes derived from meiotic cells were six times more likely to include autopolyploidy than those derived from mitotic cells (Table 1). The likelihood of sampling an autopolyploid is highly correlated with the number of studies $\left(\mathrm{R}^{2}=0.8247\right.$; Figure $\left.2 \mathrm{~B}\right)$ and the number of populations $\left(\mathrm{R}^{2}=0.8177\right.$; Figure $\left.2 \mathrm{~A}\right)$. Among species sampled for exactly two populations, the lowest possible sampling effort, $5 \%$ included an autopolyploid (Table 2).

TABLE 2. The proportions of species including an autopolyploid or aneuploid karyotype are given. All calculations are based on the trimmed dataset including only species for which exclusively two populations are sampled, to represent minimum sampling effort.

\begin{tabular}{lcc}
\hline & Proportion of species & Number of species \\
\hline Two populations counted & .05 & 12 \\
and whole number multiple karyotypes (autopolyploid) & .29 & 72 \\
Two populations counted & & \\
and all number multiple karyotypes (autopolyploid and aneuploid) & & \\
\hline
\end{tabular}

\section{Discussion}

The cumulative curve of accepted moss species names (Magill, 2010) suggests that most species of mosses have already been described. However, given their simple architectures, bryophytes in general have a more reduced morphospace to detect phenotypic signatures of evolutionary change (Bickford et al. 2007). The subtlety of morphological variation and its insufficient study using a quantitative approach make bryophytes prone to include morphologically cryptic taxa. The integration via reciprocal illumination of molecular and morphological character analyses has revealed novel morphological synapomorphies for lineages presumed to be cryptic (e.g. Heinrichs et al. 2009; Medina et al. 2019; Nieto-Lugilde et al. 2018; Hanusch et al. 2020). Based on karyotype diversity within current, largely morphologically defined moss species, we propose that many of these comprise cryptic autopolyploid and aneuploid taxa. 

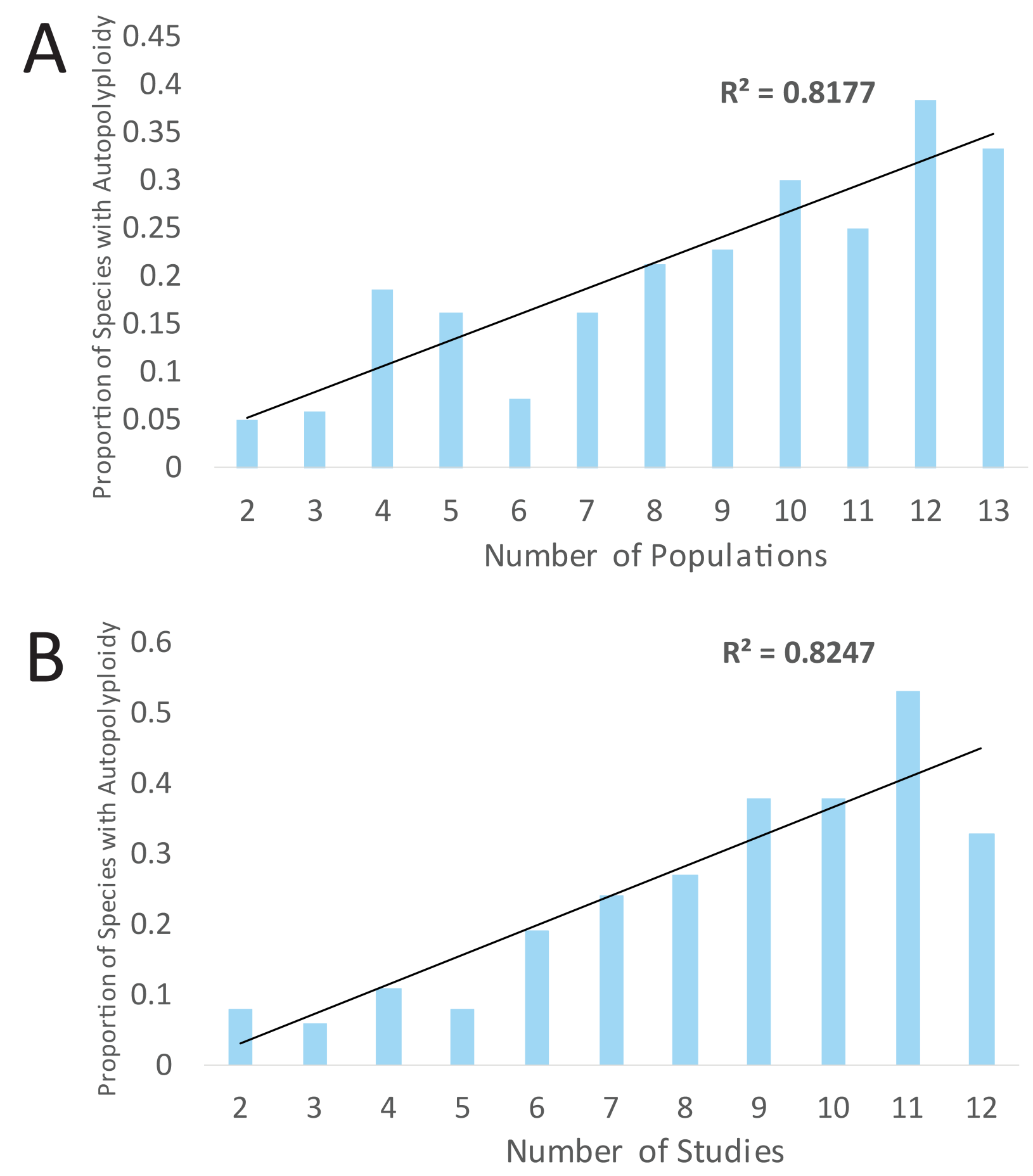

FIGURE 2. A) The proportion of species with polyploidy present among all species sampled for a given number of populations (indicated on the $\mathrm{x}$-axis). A linear line of best fit is indicated, from which the $\mathrm{R}^{2}$ statistic is derived. B) The proportion of species with polyploidy present among all species sampled for a given number of studies (indicated on the $\mathrm{X}$ axis). A linear line of best fit is indicated, from which the $\mathrm{R}^{2}$ statistic is derived.

\section{Taxonomic implications of karyotype diversity}

WGD most often results in strong postzygotic reproductive isolation (Ramsey and Schemske 1998; Levin 2002), and hence polyploids are worthy of consideration as distinct species, as previously suggested for mosses by Lazarenko (1967, fide Anderson 1974). Similarly, aneuploidy reduces fertility, but does not necessarily result in an immediate end to gene flow with progenitors (Zhang et al. 2013; Pavlíková et al. 2017), such that perhaps not all distinct karyotypes, other than entire multiples, should be distinguished at the species rank. Among polyploids, allopolyploids are 
theoretically more apt to persist as distinct lineages owing to fixed heterozygosity and transgressive niche requirements (Ramsey and Schemske 2002; Oswald and Nuismer 2011; Barker et al. 2016). Autopolyploids, on the other hand, are thought to be more likely than allopolyploids to suffer from reduced fertility, inbreeding depression, and the minority cytotype exclusion principle (Levin 1975; Parisod et al. 2010). Nonetheless, in the present review, 17\% of moss species include at least one autopolyploid karyotype and 53\% include multiple autopolyploid or aneuploid karyotypes. By extrapolating these proportions to the current estimate of moss diversity of 13,053 species (Magill 2010), the number of currently unrecognized moss species would vary between 2000 , if at least one new polyploid species is described for each species including an autopolyploid karyotype, and $\sim 12,000$, if each unique karyotype, including both autopolyploids and aneuploids, is taxonomically recognized (Figure 1B). Here, the estimate considering only autopolyploid chromosome counts, or whole number multiples, is the most conservative, whereas that including aneuploid counts is the less conservative. Given that aneuploid counts are often only one chromosome short of a whole number multiple, and hence strict autopolyploid, some aneuploid counts noted in the present study may in fact represent an erroneous count. The instances of autopolyploidy and aneuploidy presented here are rather intended to represent the full range of possibilities for frequency of chromosomal and whole genome doubling events. However, even under conservative estimates of karyotypic diversity, substantial species diversity (i.e., 17\%) would remain to be described.

\section{Prevalence and frequency of karyotype variants}

In addition to a high overall incidence of autopolyploid lineages (Table 1), the frequency of autopolyploids across the most sampled orders (Supplemental Table 1), suggests that the propensity for autopolyploidy is consistent across moss phylogenetic breadth. The overall incidence of autopolyploidy is in line with other similar lines of inquiry within mosses. Kuta and Przywara (1997) and Crawford et al. (2009) also estimated the frequency of polyploids across mosses based on Fritsch (1991), defining polyploids as species with chromosome numbers above a universal threshold. Although these studies do not evaluate the implications of differences in base chromosome number or polyploidy as compared to aneuploidy, they similarly interpret the data in Fritsch (1991) to suggest that a large proportion of species $(>20 \%)$ are polyploid (Kuta and Przywara 1997) or include polyploid populations. For angiosperms, Barker et al. (2016) specifically distinguish autopolyploids from allopolyploids. They surveyed cytological data for over 4000 species and found that $13 \%$ were autopolyploid, of which $90 \%$ are taxonomically unrecognized. As they pointed out, though morphologically cryptic, autopolyploidy is likely a frequent phenomenon.

In addition to being phylogenetically ubiquitous, the data reviewed here suggest that autopolyploidy is frequent in natural populations. For species sampled for only two populations, $5 \%$ include at least one instance of autopolyploidy and $17 \%$ of sampled lineages include at least one instance of autopolyploidy (Table 1; Table 2). Autopolyploidy as a mechanism for genome doubling as well as autopolyploid lineages are seemingly frequent. The apparent frequency of autopolyploid moss lineages should inspire further investigation of the evolutionary origins and consequences of autopolyploidy and contribute to a shifting view of autopolyploids not as short-lived evolutionary dead-ends (Otto and Whitton 2000; Comai 2005), but rather as key players in moss evolution and diversification.

\section{Next Steps}

\section{Increasing karyotype sampling}

Karyotypes vary within species of mosses and, assuming that shifts in ploidy, and perhaps even changes in number of chromosomes lead to meiotic incompatibilities and reproductive isolation, they should be integrated in taxonomic delineation. While in the present study and others, autopolyploidy appears phylogenetically widespread, efforts to karyotype mosses have virtually vanished from bryological studies, leaving an enormous gap in our understanding of genome evolution in mosses, not to mention a serious loss of expertise in karyotyping. The methodology was comprehensively described by Newton $(1973 ; 1975 ; 1984)$. Using apical regions of moss modules, i.e., primarily stems, is facilitated by the availability of suitable tissue, whereas sporogenous tissue for meiotic counts, depends on sampling developing sporophytes and catching meiosis, a process that is synchronous in mosses, and not easily induced, requiring the surveying of sporophytes over perhaps many days for a successful count.

In light of the promise of integrating karyotypes in taxonomic studies, particularly in conjunction with molecular phylogenetics, and the potential significance of autopolyploidy in the evolution and diversification of mosses, we recommend resuming cytological studies, and this at various scales. 


\subsection{Phylogenetic scale: increasing species sampling}

Based on Magill's (2010) estimate of 13,053 moss species, only 11\% of taxonomically recognized moss species have been karyotyped, leaving 11,000 species without information on their karyotype (Figure 1A). A more complete picture of karyotype diversity across mosses would serve to inform research in the area of genome size and polyploid evolution subsequently.

\subsection{Intraspecific scale: increasing population sampling}

Sampling multiple populations per species may reveal ploidy variation (Figure 2). Ideally, a geographically broad and even sampling is most apt to reveal the full breadth of karyotypic diversity (Hedenäs 2020). Cytological data, when combined with molecular phylogenetic analysis, may also provide insight into the frequency of independent WGD events, as in the Atrichum undulatum and Tortula muralis complexes (Jesson et al. 2011; Košnar et al. 2012). Such karyological studies should be undertaken for at least a selection of species, contrasting geographically widespread and restricted taxa. In light of the fact that an uneven global distribution of polyploidy has been observed in both vascular and non-vascular plants, sampling multiple populations of geographically widespread species is especially important (Brochmann et al. 2004; Rice et al. 2019; Zhang et al. 2020). Karyotyping can be technically difficult and is limited by timely access to the required tissue type (e.g. actively dividing apical cells or sporocytes). Accordingly, large scale moss cytological studies may benefit from an alternative to chromosome counts, such as flow cytometry. This technique consists in estimating the size of a genome using fluorescence. It does not allow for inferences regarding chromosome number, chromosomal pairing, and chromosome type. Barring access to either method, quantifying the dimensions of various morphological structures can inform on relative genome size variation. Polyploidy is known to leave a morphological signature known as the Gigas effect, largely impacting the average size of various structures such as spore diameter (Stebbins 1950). The effective use of such genome size estimates in studies focused on karyotype variation, and thus the use of these estimates as proxies of karyotype, requires that first the relationships between genome size estimates and karyotype be established, and for this at least two, but ideally more populations must be karyotyped and characterized by flow cytometry.

\subsection{Intraspecific scale: Intensive karyotyping within populations}

Sampling a large number of individuals within a population may further inform us on the frequency of WGD. If such intensive sampling on a given population is conducted routinely over time, it may inform our understanding of the selection acting on autopolyploids. The focal taxa for such sampling may be chosen on the basis of intraspecific morphological variation, as significant shifts in cell size may be indicative of genome doubling (Mishra 1997; Robinson et al. 2018).

\subsection{Individual scale: karyotyping cells}

The most prevalent mechanism for WGD in mosses remains unknown, though four theoretical processes have been proposed: apospory, somatic doubling, diplospory (meiotic restitution), and syndiplospory (pre-meiotic genome doubling) (Crawford et al. 2009; Rensing et al. 2013). Apospory refers to the development of gametophytes directly from sporophytic tissue, i.e., bypassing the spore stage. It is easily triggered from juvenile sporophytes in vitro, but has never been documented in wild populations (Kumar and Chopra 1980; Lobachevska et al. 2005). In somatic doubling, mitotic non-disjunction produces diploid or aneuploid somatic cells (Doyle and Coate 2019). Diplospory and syndiplospory result from meiotic non-disjunction or fusion of sporocytes prior to meiosis and both lead to diploid spores. Both processes have been observed (Vaarama 1976; Smith 1978; Ramsay 1983), but it isn't known which is involved in the majority of autopolyploidization events in mosses, and hence greater attention should be devoted to identifying those perhaps rare events within single sporangia.

\section{Assessing gene flow among karyotypes}

In order to assess the consequences of WGD and its role in speciation in mosses, experimental studies focusing on gene flow between samples of distinct ploidy or karyotype is urgently needed. To fill this gap, we recommend at least two distinct directions of research to test the following hypotheses.

\subsection{Reproductive isolation between autopolyploids and progenitors}

To our knowledge, not a single bryological study has tested whether autopolyploids, and ideally newly formed artificial autopolyploids, are immediately unable to engage in sexual reproduction with their progenitor of a lower ploidy 
level. Experimental crosses are feasible among cultured mosses (von Wettstein 1924), and may broadly inform the evolutionary dynamics of karyotypes in nature.

\subsection{Autopolyploids as triggers of further polyploidization}

Inter-ploidy reproduction has been noted in angiosperms as a 'triploid bridge', or a lineage with component genomes derived from a reduced and unreduced gamete (Schinkel et al. 2017; Spoelhof et al. 2017). The presence of oddnumbered ploidy levels observed in at least some species suggests that syngamy between haploid and diploid mosses is possible (Flatberg et al. 2006; Karlin et al. 2009; Karlin and Robinson 2017). Further, polyploid lineages evidently tend not to evolve in isolation as moss species complexes have been noted in several genera including Cinclidium, Polytrichastrum, and Physcomitrium (Derda and Wyatt 2000; McDaniel et al. 2010; Wyatt et al. 2013).

\subsection{Reproductive isolation among 'conspecific' autopolyploids}

The assumed frequency of polyploids in some species suggests that either polyploids are evolutionarily successful (i.e., withstanding eradication by natural selection) or that they arise at a high rate (Barker et al. 2016). Ephemeral and recurrent polyploids rather than polyploid lineages may not constitute species by virtue of limited reproductive capacity. Independently arising autopolyploids may become reproductively isolated from each other via chromosomal rearrangements following WGD (Comai 2005). Whether chromosomal rearrangements occur in neopolyploid mosses is unknown, but if demonstrated could significantly affect the evolutionary consequences of autopolyploidization (Husband and Sabara 2004).

\section{Conclusions}

Substantial karyotype diversity is evident within taxonomically recognized species of mosses. Karyotypes reviewed here represent only a fraction of total recognized moss species diversity and hence should spur efforts not only in assessing karyotype diversity across mosses, but also in revisiting and refining taxonomic concepts in karyotyped species. This systematic and taxonomic work should be undertaken in tandem with efforts to better characterize the cellular mechanisms both producing autopolyploids and aneuploids and precluding sexual reproduction with haploid and polyploid relatives.

\section{Acknowledgements}

We are grateful to the US National Science Foundation for financial support through grants DEB-1753811 to BG, DEB-1753800 to MJ and DEB-1753673 to RM. We appreciate the feedback from reviewers, which greatly improved this manuscript.

\section{References}

Anderson, L.E. (1974) Bryology 1947-1972. Annals of the Missouri Botanical Garden 61: 56-85. https://doi.org/10.2307/2395185

Barker, M.S., Arrigo, N., Baniaga, A.E., Li, Z. \& Levin, D.A. (2016) On the relative abundance of autopolyploids and allopolyploids. New Phytologist 210: 391-398.

https://doi.org/10.1111/nph.13698

Beck, J.B., Windham, M.D., Yatskievych, G. \& Pryer, K.M. (2010) A diploids-first approach to species delimitation and interpreting polyploid evolution in the fern genus Astrolepis (Pteridaceae). Systematic Botany 35: 223-234. https://doi.org/10.1600/036364410791638388

Beike, A.K., von Stackelberg, M., Schallenberg-Rüdinger, M., Hanke, S.T., Follo, M., Quandt, D., McDaniel, S., Reski, R., Tan, B. \& Rensing, S.A. (2014) Molecular evidence for convergent evolution and allopolyploid speciation within the PhyscomitriumPhyscomitrella species complex. BMC Evolutionary Biology 14: 158.

https://doi.org/10.1186/1471-2148-14-158 
Bickford, D., Lohman, D.J., Sodhi, N.S., Ng, P.K.L., Meier, R., Winker, K., Ingram, K.K. \& Das, I. (2007) Cryptic species as a window on diversity and conservation. Trends in Ecology \& Evolution 22: 148-155.

https://doi.org/10.1016/j.tree.2006.11.004

Brochmann, C., Brysting, A.K., Alsos, I.G., Borgen, L., Grundt, H.H., Scheen, A.C. \& Elven, R. (2004) Polyploidy in arctic plants. Biological Journal of the Linnaean Society 82: 521-536.

https://doi.org/10.1111/j.1095-8312.2004.00337.x

Comai, L. (2005) The advantages and disadvantages of being polyploid. Nature Reviews Genetics 6: 836-846. https://doi.org/10.1038/nrg1711

Costich, D.E., Friebe, B., Sheehan, M.J., Casler, M.D. \& Buckler, E.S. (2010) Genome-size variation in switchgrass (Panicum virgatum): flow cytometry and cytology reveal rampant aneuploidy. The Plant Genome 3: 130-141. https://doi.org/10.3835/plantgenome2010.04.0010

Crawford, M., Jesson, L.K. \& Garnock-Jones, P.J. (2009)Correlated evolution of sexual system and life-history traits in mosses. Evolution 63: $1129-1142$. https://doi.org/10.1111/j.1558-5646.2009.00615.x

Cui, L., Wall, P.K., Leebens-Mack, J.H., Lindsay, B.G., Soltis, D.E., Doyle, J.J., Soltis, P.S., Carlson, J.E., Arumuganathan, K., Barakat, A., Albert, V.A., Ma, H. \& dePamphilis, C.W. (2006) Widespread genome duplications throughout the history of flowering plants. Genome Research 16: 738-749. https://doi.org/10.1101/gr.4825606

Derda, G.S. \& Wyatt, R. (2000) Isozyme evidence regarding the origins of three allopolyploid species of Polytrichastrum (Polytrichaceae, Bryophyta). Plant Systematics and Evolution 22: 37-53. https://doi.org/10.1007/BF00985369

Doyle, G.G. (1986) Aneuploidy and inbreeding depression in random mating and self-fertilizing autotetraploid populations. Theoretical and Applied Genetics 72: 799-806. https://doi.org/10.1007/BF00266548

Doyle, J.J. \& Coate, J.E. (2019) Polyploidy, the nucleotype, and novelty: the impact of genome doubling on the biology of the cell. International Journal of Plant Sciences 180: 1-52. https://doi.org/10.1086/700636

Eriksson, J.S., Blanco-Pastor, J.L., Sousa, F., Bertrand, Y.J.K. \& Pfeil, B.E. (2017) A cryptic species produced by autopolyploidy and subsequent introgression involving Medicago prostrata (Fabaceae). Molecular Phylogenetics and Evolution 107: $367-381$. https://doi.org/10.1016/j.ympev.2016.11.020

Flatberg, K.I., Thingsgaard, K. \& Såstad, S.M. (2006) Interploidal gene flow and introgression in bryophytes: Sphagnum girgensohnii $\times$ S. russowii, a case of spontaneous neotriploidy. Journal of bryology 28: 27-37. https://doi.org/10.1179/174328206X90459

Fritsch, R. (1991) Index to bryophyte chromosome counts. Bryophytorum Bibliotheca 40: 1-352.

Gao, B., Chen, M.X., Li, X.S., Liang, Y.Q., Zhang, D.Y., Wood, A.J., Oliver, M.J. \& Zhang, J.H. (2020) Integrated phylogenomic analyses reveal recurrent ancestral large-scale duplication events in mosses. Journal of Systematics and Evolution. https://doi.org/10.1101/603191

Goffinet, B. (2009) Morphology, anatomy, and classification of the Bryophyta. In: Goffinet, B. \& Shaw, J. (Eds.) Bryophyte Biology. Cambridge University Press, London, pp.55-138.

Grusz, A.L. (2016) A current perspective on apomixis in ferns. Journal of Systematics and Evolution 54: 656-665. https://doi.org/10.1111/jse.12228

Hanusch, M., Ortiz, E.M., Patiño, J. \& Schaefer, H. (2020) Biogeography and integrative taxonomy of Epipterygium (Mniaceae, Bryophyta). Taxon 69: 1150-1171. https://doi.org/10.1002/tax.12324

Hedenäs, L. (2020) Cryptic speciation revealed in Scandinavian Racomitrium lanuginosum (Hedw.) Brid.(Grimmiaceae). Journal of Bryology 42: 117-127. https://doi.org/10.1080/03736687.2020.1722923

Heinrichs, J., Hentschel, J., Feldberg, K., Bombosch, A. \& Schneider, H. (2009) Phylogenetic biogeography and taxonomy of disjunctly distributed bryophytes. Journal of Systematics and Evolution 47: 497-508. https://doi.org/10.1111/j.1759-6831.2009.00028.x

Henry, I.M., Dilkes, B.P., Miller, E.S., Burkart-Waco, D. \& Comai, L. (2010) Phenotypic consequences of aneuploidy in Arabidopsis thaliana. Genetics 186: 1231-1245. https://doi.org/10.1534/genetics.110.121079 
Husband, B.C. (2004) The role of triploid hybrids in the evolutionary dynamics of mixed-ploidy populations. Biological Journal of the Linnean Society 82: 537-546. https://doi.org/10.1111/j.1095-8312.2004.00339.x

Husband, B.C., Baldwin, S.J. \& Suda, J. (2013) The incidence of polyploidy in natural plant populations: major patterns and evolutionary processes. In: Leitch, I., Greilhuber, J., Dolezel, J. \& Wendel, J. (Eds.) Plant Genome Diversity. volume 2. Springer, Vienna, pp. $255-276$.

https://doi.org/10.1007/978-3-7091-1160-4_16

Husband, B.C. \& Sabara, H.A. (2004) Reproductive isolation between autotetraploids and their diploid progenitors in fireweed, Chamerion angustifolium (Onagraceae). New Phytologist 161: 703-713.

https://doi.org/10.1046/j.1469-8137.2004.00998.x

Jauhar, P.P. (2003) Formation of 2n gametes in durum wheat haploids: sexual polyploidization. Euphytica 133: 81-94. https://doi.org/10.1023/A:1025692422665

Jesson, L.K., Cavanagh, A.P. \& Perley, D.S. (2011) Polyploidy influences sexual system and mating patterns in the moss Atrichum undulatum sensu lato. Annals of Botany 107: 135-143.

https://doi.org/10.1093/aob/mcq216

Jiao, Y., Wickett, N.J., Ayyampalayam, S., Chanderbali, A.S., Landherr, L., Ralph, P.E., Tomsho, L.P., Hu, Y., Liang, H., Soltis, P.S., Soltis, D.E., Clifton, S.W., Schlarbaum, S.E., Schuster, S.C., Ma, H., Leebens-Mack, J. \& de Pamphilis, C.W. (2011) Ancestral polyploidy in seed plants and angiosperms. Nature 473: 97-100.

https://doi.org/10.1038/nature09916

Karlin, E.F., Boles, S.B., Ricca, M., Temsch, E.M., Greilhuber, J. \& Shaw, A.J. (2009) Three-genome mosses: complex double allopolyploid origins for triploid gametophytes in Sphagnum. Molecular Ecology 18: 1439-1454.

https://doi.org/10.1111/j.1365-294X.2009.04113.x

Karlin, E.F. \& Robinson, S.C. (2017) Update on the Holantarctic Sphagnum $\times$ falcatulum sl (Sphagnaceae) complex: S. irritans is associated with the allo-diploid plants. Journal of Bryology 39: 8-15.

https://doi.org/10.1080/03736687.2016.1218674

Köhler, C., Scheid, O.M. \& Erilova, A. (2010) The impact of the triploid block on the origin and evolution of polyploid plants. Trends in Genetics 26: 142-148. https://doi.org/10.1016/j.tig.2009.12.006

Košnar, J., Herbstová, M., Kolář, F., Koutecký, P. \& Kučera, J. (2012) A case study of intragenomic ITS variation in bryophytes: assessment of gene flow and role of polyploidy in the origin of European taxa of the Tortula muralis (Musci: Pottiaceae) complex. Taxon 61: 709-720. https://doi.org/10.1002/tax.614001

Kumar, P.K. \& Chopra, R.N. (1980) Occurrence of apogamy and apospory from the capsules of Funaria hygrometrica Hedw. Cryptogamie, Bryologie, et Lichénologie 2: 197-200.

Kuta, E. \& Przywara, L. (1997) Polyploidy in mosses. Acta Biologica Cracoviensia. Series Botanica 39: 17-26.

Lazarenko, A.S. (1967) Polyploidy in the evolution of Musci. Tsitologiya i Genetika 1: 15-26.

Levin, D.A. (1975) Minority cytotype exclusion in local plant populations. Taxon 24: 35-43.

https://doi.org/10.2307/1218997

Levin, D.A. (2002) The role of chromosomal change in plant evolution. Oxford University Press, London.

Lewis, W.H. (1980) Polyploidy in species populations. Basic Life Sciences. Springer, Boston, pp. 103-144. https://doi.org/10.1007/978-1-4613-3069-1_6

Lobachevska, O., Kyjak, N., Khorkavtsiv, O., Dovgalyuk, A., Kit, N., Klyuchivska, O., Stoikab, R., Ripetskya, R. \& Cove, D. (2005) Influence of metabolic stress on the inheritance of cell determination in the moss, Pottia intermedia. Cell Biology International 29: 181-186.

https://doi.org/10.1016/j.cellbi.2005.02.001

Luceño, M. \& Castroviejo, S. (1991) Agmatoploidy in Carex laevigata (Cyperaceae). Fusion and fission of chromosomes as the mechanism of cytogenetic evolution in Iberian populations. Plant Systematics and Evolution 177: 149-159. https://doi.org/10.1007/BF00937952

Magill, R.E. (2010) Moss diversity: new look at old numbers. Phytotaxa 9: 167-174. https://doi.org/10.11646/phytotaxa.9.1.9

Mandáková, T. \& Lysak, M.A. (2018) Post-polyploid diploidization and diversification through dysploid changes. Current Opinion in Plant Biology 42: 55-65.

https://doi.org/10.1016/j.pbi.2018.03.001 
Marks, G.E. (1966) The origin and significance of intraspecific polyploidy: experimental evidence from Solanum chacoense. Evolution 20: $552-557$. https://doi.org/10.1111/j.1558-5646.1966.tb03385.x

McDaniel, S.F., Von Stackelberg, M., Richardt, S., Quatrano, R.S., Reski, R. \& Rensing, S.A. (2010) The speciation history of the Physcomitrium-Physcomitrella species complex. Evolution 64: 217-231. https://doi.org/10.1111/j.1558-5646.2009.00797.x

Medina, R., Johnson, M.G., Liu, Y., Wickett, N.J., Shaw, A.J. \& Goffinet, B. (2019) Phylogenomic delineation of Physcomitrium (Bryophyta: Funariaceae) based on targeted sequencing of nuclear exons and their flanking regions rejects the retention of Physcomitrella, Physcomitrium and Aphanorrhegma. Journal of Systematics and Evolution 57: 404-417. https://doi.org/10.1111/jse.12516

Mishra, M.K. (1997) Stomatal characteristics at different ploidy levels in Coffea L. Annals of Botany 80: 689-692. https://doi.org/10.1006/anbo.1997.0491

Natcheva, R. \& Cronberg, N. (2004) What do we know about hybridization among bryophytes in nature? Canadian Journal of Botany 82 : $1687-1704$. https://doi.org/10.1139/b04-139

Newton, M.E. (1973) Chromosome studies in some New Zealand and Jamaican bryophytes. Journal of Bryology 7: $399-403$. https://doi.org/10.1179/jbr.1973.7.3.399

Newton, M.E. (1975) Chromosome studies in some British bryophytes. Journal of Bryology 8: 365-382. https://doi.org/10.1179/jbr.1975.8.3.365

Newton, M.E. (1984) Cytogenetics of bryophytes. In: Dyer, A. \& Duckett, J. (Eds.) Experimental Biology of Bryophytes. Academic Press, London, pp. 65-96.

Nieto-Lugilde, M., Werner, O., McDaniel, S.F., Koutecký, P., Kučera, J., Rizk, S.M. \& Ros, R.M. (2018) Peripatric speciation associated with genome expansion and female-biased sex ratios in the moss genus Ceratodon. American Journal of Botany 105: $1009-1020$. https://doi.org/10.1002/ajb2.1107

Oswald, B.P. \& Nuismer, S.L. (2011) A unified model of autopolyploid establishment and evolution. The American Naturalist 178: 687700 . https://doi.org/10.1086/662673

Otto, S.P. \& Whitton, J. (2000) Polyploid incidence and evolution. Annual Review of Genetics 34: 401-437. https://doi.org/10.1146/annurev.genet.34.1.401

Parisod, C., Holderegger, R. \& Brochmann, C. (2010) Evolutionary consequences of autopolyploidy. New Phytologist 186 : 5-17. https://doi.org/10.1111/j.1469-8137.2009.03142.x

Patel, N., Li, C.X., Zhang, L.B. \& Barrington, D.S. (2018) Biodiversity and apomixis: Insights from the East-Asian holly ferns in Polystichum section Xiphopolystichum. Molecular Phylogenetics and Evolution 127: 345-355. https://doi.org/10.1016/j.ympev.2018.05.003

Pavlíková, Z., Paštová, L. \& Münzbergová, Z. (2017) Synthetic polyploids in Vicia cracca: methodology, effects on plant performance and aneuploidy. Plant Systematics and Evolution 303: 827-839.

https://doi.org/10.1007/s00606-017-1414-y

Ramsay, H.P. (1983) Cytology of mosses. In: Schuster, R. (Ed.) New manual of bryology vol 1. Hattori Botanical Society, pp. $149-221$.

Ramsey, J. \& Schemske, D.W. (1998) Pathways, mechanisms, and rates of polyploid formation in flowering plants. Annual Review of Ecology and Systematics 29: 467-501. https://doi.org/10.1146/annurev.ecolsys.29.1.467

Ramsey, J. \& Schemske, D.W. (2002) Neopolyploidy in flowering plants. Annual Review of Ecology and Systematics 33: 589-639.

Randolph, L.F. (1935) Cytogenetics of tetraploid maize. Journal of Agricultural Research 50: 591-605.

Rensing, S.A., Beike, A.K. \& Lang, D. (2013) Evolutionary importance of generative polyploidy for genome evolution of haploiddominant land plants. In: Leitch, I., Greilhuber, J., Dolezel, J. \& Wendel, J. (Eds.) Plant Genome Diversity Volume 2. Springer, Vienna, pp. 295-305. https://doi.org/10.1007/978-3-7091-1160-4_18

Ricca, M. \& Shaw, A.J. (2010) Allopolyploidy and homoploid hybridization in the Sphagnum subsecundum complex (Sphagnaceae: Bryophyta). Biological Journal of the Linnean Society 99: 135-151. https://doi.org/10.1111/j.1095-8312.2009.01340.x

Rice, A., Šmarda, P., Novosolov, M., Drori, M., Glick, L., Sabath, N., Sahi, M., Belmaker, J. \& Mayrose, I. (2019) The global biogeography of polyploid plants. Nature Ecology \& Evolution 3: 265-273. https://doi.org/10.1038/s41559-018-0787-9 
Robinson, D.O., Coate, J.E., Singh, A., Hong, L., Bush, M., Doyle, J.J. \& Roeder, A.H. (2018) Ploidy and size at multiple scales in the Arabidopsis sepal. The Plant Cell 30: 2308-2329.

https://doi.org/10.1105/tpc. 18.00344

Schemske, D.W. (2000) Understanding the origin of species. Evolution 54: 1069-1073. https://doi.org/10.1111/j.0014-3820.2000.tb00111.x

Schinkel, C.C., Kirchheimer, B., Dullinger, S., Geelen, D., De Storme, N. \& Hörandl, E. (2017) Pathways to polyploidy: indications of a female triploid bridge in the alpine species Ranunculus kuepferi (Ranunculaceae). Plant Systematics and Evolution 303: 10931108. https://doi.org/10.1007/s00606-017-1435-6

Shaw, A.J. (2009) Bryophyte species and speciation. In: Goffinet, B., Shaw, J. (eds.) Bryophyte biology, Cambridge University Press, London, pp.55-138.

Smith, A.J.E. (1978) Cytogenetics, biosystematics and evolution in the Bryophyta. In: Advances in botanical research. Academic Press, Cambridge, pp. 195-276. https://doi.org/10.1016/S0065-2296(08)60331-6

Soltis, D.E., Soltis, P.S., Schemske, D.W., Hancock, J.F., Thompson, J.N., Husband, B.C. \& Judd, W.S. (2007) Autopolyploidy in angiosperms: have we grossly underestimated the number of species? Taxon 56: 13-30.

Soltis, D.E., Visger, C.J. \& Soltis, P.S. (2014) The polyploidy revolution then and now: Stebbins revisited. American Journal of Botany 101: $1057-1078$. https://doi.org/10.3732/ajb.1400178

Spoelhof, J.P., Soltis, P.S. \& Soltis, D.E. (2017) Pure polyploidy: closing the gaps in autopolyploid research. Journal of Systematics and Evolution 55: 340-352. https://doi.org/10.1111/jse.12253

Stebbins Jr., G.L. (1947) Types of polyploids: their classification and significance. In: Demerec, M. (Ed.) Advances in genetics. Academic Press, Cambridge, pp. 403-429. https://doi.org/10.1016/S0065-2660(08)60490-3

Stebbins, G.L. (1950) Variation and Evolution in Plants. Columbia University Press, New York, 623 pp. https://doi.org/10.7312/steb94536

Svačina, R., Sourdille, P., Kopecký, D., \& Bartoš, J. (2020) Chromosome pairing in polyploid grasses. Frontiers in Plant Science 11: 1056. https://doi.org/10.3389/fpls.2020.01056

Tate, J.A., Soltis, D.E. \& Soltis, P.S. (2005) Polyploidy in plants. In: Gregory, T. (Ed.) The Evolution of the Genome. Academic Press, Cambridge, pp. 371-426. https://doi.org/10.1016/B978-012301463-4/50009-7

Vaarama, A. (1976) The cytotaxonomic approach to the study of bryophytes. Journal of Hattori Botanical Laboratory 41: 7-12.

Vickery, R.K. (1995) Speciation by aneuploidy and polyploidy in Mimulus (Scrophulariaceae). The Great Basin Naturalist 55: $174-176$.

Vitt, D.H. (1971) The infrageneric evolution, phylogeny, and taxonomy of the genus Orthotrichum (Musci) in North America. Nova Hedwigia 21: 683-711.

Wettstein, F.V. (1924) Morphologie und Physiologie des Formwechsels der Moose auf genetischer Grundlage. I. Zeitschrift für induktive Abstammungs-und Vererbungslehre 33: 1-236. https://doi.org/10.1007/BF01762372

Wood, T.E., Takebayashi, N., Barker, M.S., Mayrose, I., Greenspoon, P.B. \& Rieseberg, L.H. (2009) The frequency of polyploid speciation in vascular plants. Proceedings of the National Academy of Sciences 106 (33): 13875-13879. https://doi.org/10.1073/pnas.0811575106

Wyatt, R., Odrzykoski, I.J. \& Stoneburner, A. (2013) Isozyme evidence regarding the nature of polyploidy in the moss genus Cinclidiu (Mniaceae). The Bryologist 116: 229-237. https://doi.org/10.1639/0007-2745-116.3.229

Wyatt, R., Odrzykoski, I.J., Stoneburner, A., Bass, H.W. \& Galau, G.A. (1988) Allopolyploidy in bryophytes: multiple origins of Plagiomnium medium. Proceedings of the National Academy of Sciences 85: 5601-5604. https://doi.org/10.1073/pnas.85.15.5601

Xiong, Z., Gaeta, R.T. \& Pires, J.C. (2011) Homoeologous shuffling and chromosome compensation maintain genome balance in resynthesized allopolyploid Brassica napus. Proceedings of the National Academy of Sciences 108: 7908-7913. https://doi.org/10.1073/pnas.1014138108 
Zhang, H., Bian, Y., Gou, X., Zhu, B., Xu, C., Qi, B., Li, N., Rustgi, S., Zhou, H. Han, F., Jiang, J., von Wettstein, D. \& Jiang, J. (2013) Persistent whole-chromosome aneuploidy is generally associated with nascent allohexaploid wheat. Proceedings of the National Academy of Sciences 110: 3447-3452.

https://doi.org/10.1073/pnas.1300153110

Zhang, J., Wang, M., Guo, Z., Guan, Y., Guo, Y. \& Yan, X. (2020) Variation in ploidy level and genome size of Cynodon dactylon (L.) Pers. along a latitudinal gradient. Folia Geobotanica 54: 267-278.

https://doi.org/10.1007/s12224-019-09359-y

SUPPLEMENTAL TABLE 1. For each of the six most sampled families, the proportion of species with two or more populations sampled is given, and the proportion of those species with autopolyploidy present is indicated. The number of species comprising each proportion is given.

\begin{tabular}{lllll}
\hline Order & $\begin{array}{l}\text { Total number of } \\
\text { species karyotyped }\end{array}$ & $\begin{array}{l}\text { Number of species with 2+ } \\
\text { populations karyotyped }\end{array}$ & $\begin{array}{l}\text { Proportion of species with } \\
\text { autopolyploid karyotype }\end{array}$ & $\begin{array}{l}\text { Number of species with } \\
\text { autopolyploid karyotype }\end{array}$ \\
\hline Bryales & 145 & 108 & .32 & 35 \\
Dicranales & 197 & 127 & .13 & 17 \\
Hypnales & 485 & 291 & .13 & 38 \\
Orthotrichales & 74 & 45 & .11 & 5 \\
Polytrichales & 71 & 54 & .27 & 15 \\
& & & & .15 \\
\hline
\end{tabular}

SUPPLEMENTAL FILE 1. A list of literature sources for karyotypic data.

SUPPLEMENTAL FILE 2. All species and karyotypic data

SUPPLEMENTAL FILE 3. All species and karyotypic data with names updated according to taxonomic changes since publication. 